\title{
Fatigue Crack Initiation in an Interstitial Free Steel
}

\author{
N. NARASAIAH, P. C. CHAKRABORTI, ${ }^{1)}$ R. MAITI') and K. K. RAY ${ }^{21}$
}

Formerly at Department of Metallurgical and Materials Engineering, Indian Institute of Technology, Kharagpur-721302, India. Now at Currently with National Metallurgical Laboratory, Jamshedpur-831007, India.

1) Department of Metallurgical Engineering, Jadavpur University, Kolkata-700 032, India.

2) Department of Metallurgical and Materials Engineering, Indian Institute of Technology, Kharagpur-721302, India.

(Received on July 23, 2004; accepted in final form on September 17, 2004)

The initiation of small cracks has been studied on dumble-shaped plate type specimens of an interstitial free (IF) steel at the load ratio of $R=0$ under varied cyclic stress amplitudes between 0.6 and 1.0 of yield stress. Nucleation of cracks were observed at ferrite-ferrite grain boundary (FFGB) as well as inside ferrite grain body (FGB), but the former location was found to be the preferred one. The average length of FFGB cracks is found larger than that of the FGB cracks for identical cyclic loading conditions. The formation of slip bands inside the grain body, slip band impingement at grain boundary and elastic-plastic incompatibility synergistically influence the event of crack initiation in the investigated steel. In addition, nucleation of voids inside slip bands was found to be a new phenomenon associated with the above possibilities to affect the nucleation of cracks in the investigated steel.

KEY WORDS: fatigue; crack initiation; small crack; interstitial free steel.

\section{Introduction}

The development of interstitial free (IF) steels has been a milestone for achieving high drawability of sheet steels and is being increasingly considered as materials for the automotive industry. Interstitial free steels are necessarily low carbon variety from which the carbon and nitrogen are scavenged out as precipitates by the addition of $\mathrm{Ti}$ and/or $\mathrm{Nb}$ instead of allowing these elements to remain in solid solution, in order to achieve the required high drawability property. ${ }^{1)}$ The initial emphasis on the development of this steel has been laid on its manufacturing route and in seeking correlation between structure (related to grain size, texture and anisotropy ratio etc.) and properties (related to strength, formability and drawability etc.) for varied material chemistry and thermo-mechanical treatment. ${ }^{1-4)}$ Since this steel is primarily developed for automotive application, its cyclic damage behavior and fatigue properties are of paramount interest, but unfortunately investigations in this direction are limited. The fatigue damage in a structural component consists of several sequential stages like: (i) sub-structural changes causing nucleation of micro-cracks, (ii) formation of micro-cracks, (iii) growth and coalescence of micro-cracks to a dominant macro-crack, (iv) stable propagation of the dominant macro-crack, and finally (v) structural instability causing complete fracture. The design philosophy against fatigue damage either considers all the stages or it considers only the stable sub-critical propagation of the dominant macro-crack. It is well conceived by now that a large percentage of fatigue life of smooth specimens are spent in the domain of crack nucleation and small/short crack growth, especially in the emerging clean structural materials in high cycle fatigue. It is thus imperative to gather more knowledge about crack nucleation and about small/short crack growth behavior in this grade of steel. This report deals only with the crack initiation event in an IF steel.

The instant of crack initiation is difficult to separate from the stage of small/short crack propagation in a material. Any crack with all three dimensions small is defined here as 'small crack', ; the 'short cracks', on the other hand, are known to possess two small dimensions and the third one of macroscopic size. Interestingly, the developments related to the mechanisms of crack nucleation are found to be mostly associated with concepts related to sub-structural features like dislocations, dislocation-vacancy complexes, dislocation dipoles etc., ${ }^{6-8)}$ whereas the models describing small/short crack growth behavior in materials emphasizes on accounting the microstructural features like grain boundaries, precipitates, second phase particles etc. ${ }^{9-11)}$ Particularly in IF steel, the phenomenon of crack initiation and small crack growth are of great scientific interest because the cyclic damage of the predominantly bcc ferritic structure would be governed by the typical behavior of screw dislocations having extended core inducing slip asymmetry in cyclic deformation ${ }^{12,13)}$ during the initiation stage whereas its growth would probably be controlled by the grain size and the submicroscopic precipitate particles. In some recent communications, ${ }^{14,15)}$ two of the present authors have extended some understanding about the influence of microstructure on the initiation and short crack growth behavior in structural steels having ferrite-pearlite structures. In the present communication the events associated with crack nucleation in a predominantly single phase 
Table 1. Composition of the investigated steel (in weight percentage).

\begin{tabular}{|c|c|c|c|c|c|c|c|c|c|c|c|}
\hline $\mathrm{C}$ & $\mathrm{Mn}$ & $\mathrm{Si}$ & $\mathrm{P}$ & $\mathrm{S}$ & $\mathrm{Al}$ & $\mathrm{Ti}$ & $\mathrm{Ni}$ & $\mathrm{V}$ & $\mathrm{N}$ & $\mathrm{Mo}$ & $\mathrm{Nb}$ \\
\hline 0.003 & 0.13 & 0.009 & 0.012 & 0.009 & 0.06 & 0.052 & 0.01 & 0.001 & 0.0034 & 0.001 & 0.001 \\
\hline
\end{tabular}

IF steel is being addressed. The major aims of this report are to identify the preferred crack nucleation sites in the selected steel and to distinguish the possible mechanisms associated with the various types of cracks observed in the material.

\section{Experimental Procedure}

An interstitial free (IF) steel, commercially used for automobile applications, has been used in this investigation. The steel was obtained as hot rolled plates (of approximate dimension $150 \times 150 \times 18 \mathrm{~mm}$ ) with rolling directions marked on them as courtesy of Tata Iron and Steel Company Ltd., Jamshedpur, India. These were collected as transfer bars just after processing in a roughing mill. The chemical composition of the steel is shown in Table 1. Samples for microstructural studies were ground with emery paper and were polished first using alundum and finally using $0.25 \mu \mathrm{m}$ diamond paste. The average volume fraction of the inclusions and their average size were estimated on the polished specimens following standard methods. ${ }^{16,17)}$ These were found to be $0.06 \%$ and $2.9 \mu \mathrm{m}$ respectively. The polished samples were etched with $2 \%$ nital solution to reveal the microstructure. Optical microscopic examination indicated the steel to contain predominantly ferrite as shown in Fig. 1. The average grain size was found to be $64.4 \pm 1.3 \mu \mathrm{m}$ by linear intercept method.

Cylindrical specimens of $5 \mathrm{~mm}$ gauge diameter and $20 \mathrm{~mm}$ gauge length were used for the determination of tensile properties of the steel following ASTM standard E803. ${ }^{18)}$ These tests were carried out using a Universal testing machine (Schimadzu, model: AG-5000G) at a nominal strain rate of $4.2 \times 10^{-4} \mathrm{~s}^{-1}$ at room temperature. The average yield $\left(\sigma_{\mathrm{y}}\right)$ and tensile $\left(\sigma_{\mathrm{t}}\right)$ strength of the material were found to be $94 \pm 2$ and $238 \pm 3 \mathrm{MPa}$ respectively, whereas the uniform and the total elongation were estimated as $35 \pm 0.8$ and $45 \pm 0.5 \%$ respectively.

The fatigue studies were carried out on small hourglass type flat specimens, made from the as-received material as shown in Fig. 2. One of the flat surfaces of these samples was ground, polished, and etched to reveal the microstructure. The fatigue tests were performed with the help of an Instron machine (model: 8501) using sinusoidal wave at a frequency of $10 \mathrm{~Hz}$ at room temperature (approximately $298 \mathrm{~K}$ ) in the laboratory air. The tests were conducted at various stress ranges keeping the maximum stress as 0.6 to $1.0 \sigma_{\mathrm{y}}$ of the steel while maintaining the minimum stress as zero. Each test at different applied stress ranges was carried out for $2 \times 10^{4}$ cycles. After the fatigue test, the specimens were examined under a scanning electron microscope (JEOL model: 5800) to locate the crack initiation sites. A series of photographs with careful demarcation of the loading direction of the specimens were taken from numerous locations of interest, which exhibited small cracks. The average length and orientation of the small cracks and their location in the microstructure were next examined.

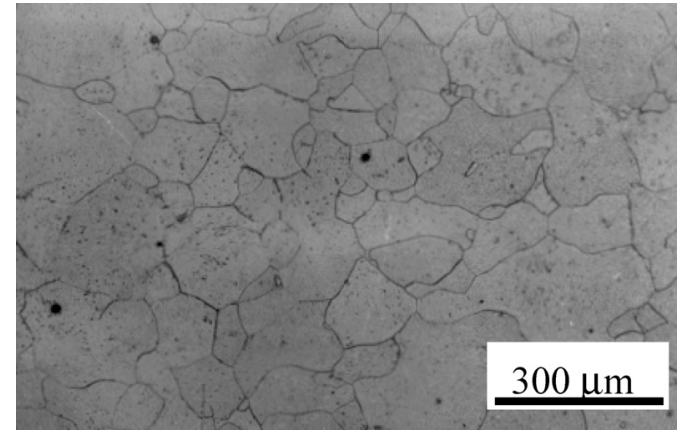

Fig. 1. Typical microstructure of the investigated steel.

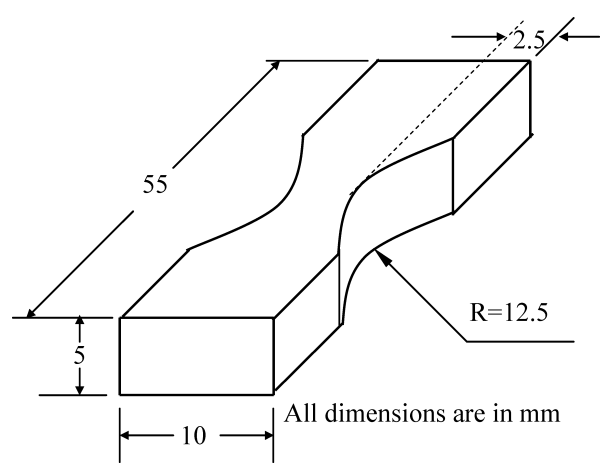

Fig. 2. Specimen configuration used for crack initiation studies.

\section{Results and Discussion}

The locations at which cracks initiate in the microstructure of IF steel and the nature of such cracks after a stage of growth to a size where these can be conveniently examined by scanning electron microscopy, are the primary content of this study. The cracks thus examined may be simply termed as "small cracks". In order to understand the influence of the microstructure on the nature of the initiated cracks, the fatigue tests have been carried out in a manner that most of the cracks are generated with negligible growth. The size range of the observed cracks was found to be 2-43, 7-96 and $7-60 \mu \mathrm{m}$ at $\Delta \sigma=0.6,0.8$ and $1.0 \sigma_{\mathrm{y}}$ respectively. The cracks exhibit a wide size range under identical $\Delta \sigma$ and number of cycles $(N)$; because, when one type of cracks gets generated with the lower bound values of the size range, a number of alternate cracks are found to nucleate and grow to sizes near the upper bound. A series of these cracks were photographed using a scanning electron microscope at suitable magnifications so that their maximum dimension can be measured conveniently.

The SEM examinations of the polished and etched surfaces of the fatigue tested specimens of the investigated steel indicated that the location at which crack initiation occurs in the microstructure of this steel is either at the grain boundary or in the grain body. Some typical grain boundary and grain body cracks are shown in Fig. 3 and Fig. 4 respectively. Interestingly no crack was observed to originate from any inclusion site, as illustrated in Fig. 5. Thus the ob- 

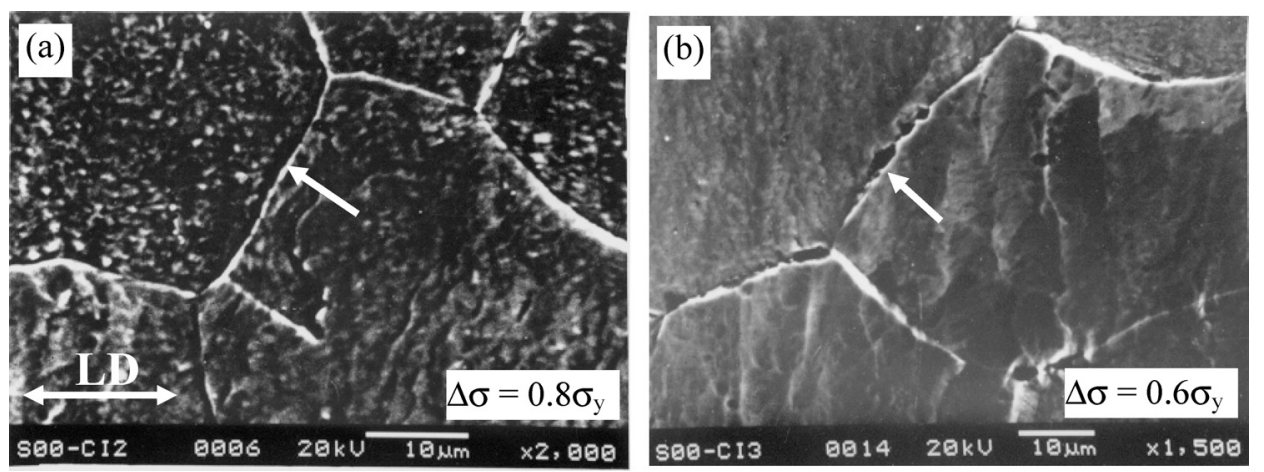

Fig. 3. Typical ferrite grain boundary cracks in the investigated steel. The loading direction (LD) is common in both the figures and has been marked in (a): (a) well developed grain boundary crack oriented almost at $45^{\circ}$ to the loading axis and (b) voids and splits at grain boundary together with slip bands.
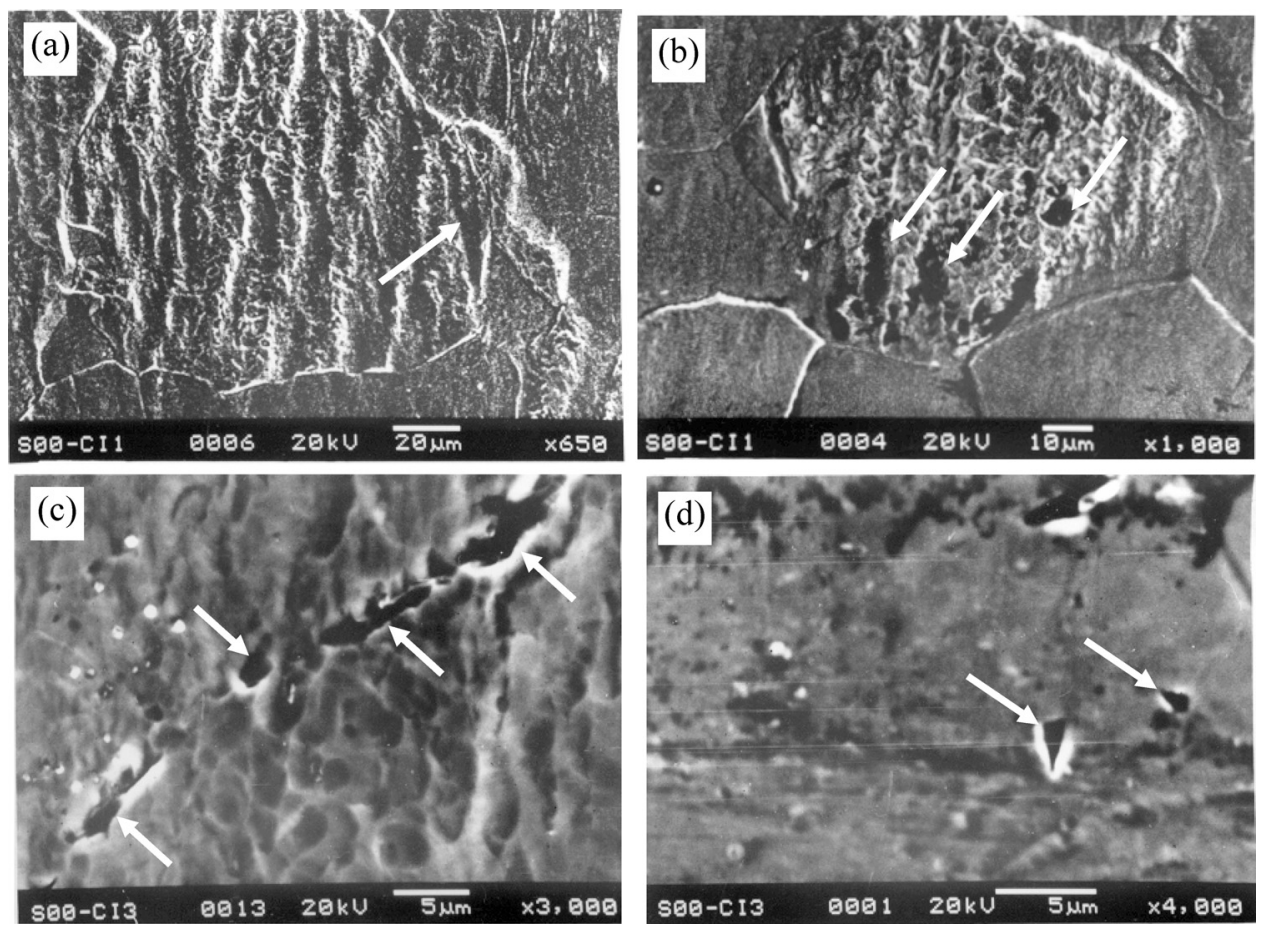

Fig. 4. A set of typical ferrite grain body cracks in the investigated steel: (a) formation of a crack along slip band, (b) formation of irregular voids and cracks along slip bands, (c) coalescence of voids to initiate cracks with low aspect ratio and (d) cracks with sharp tips.

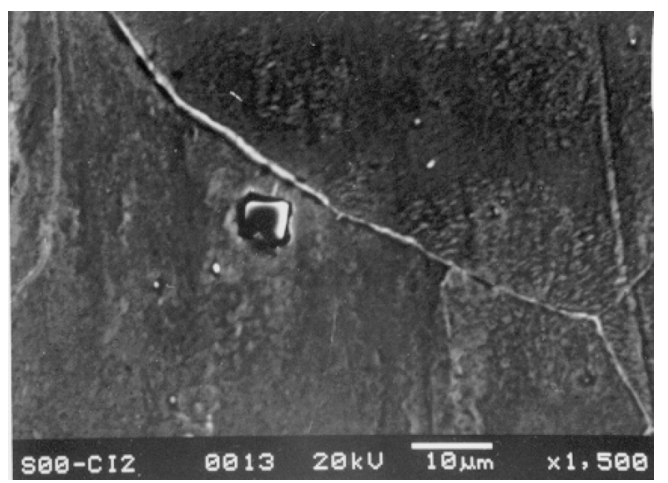

Fig. 5. A typical inclusion in the steel showing no crack initiation $\left(\Delta \sigma=0.8 \sigma_{\mathrm{y}}\right)$.

served crack initiation sites in the selected IF steel can be categorized as: (a) grain boundary and (b) grain body cracks based on their position in the microstructure.

\subsection{Crack Initiation at Grain Boundary}

The size and the distribution of the grain boundary cracks were first analyzed at different applied fatigue stress ranges $(\Delta \sigma)$ and the average lengths of these cracks at $\Delta \sigma=0.6,0.8$ and $1.0 \sigma_{\mathrm{y}}$ were found to be $14 \pm 6,38 \pm 7$ and $34 \pm 4 \mu \mathrm{m}$ respectively. These results indicate that the average size of the initiated cracks at the lowest stress range of $0.6 \sigma_{\mathrm{y}}$ is considerably smaller than that at higher stress ranges. These results thus naturally infer that some of the initiated cracks at higher $\Delta \sigma$ got the chance to grow. Typical distributions of the crack sizes at the imposed stress ranges are shown in Fig. 6. An examination of the crack size distribution indicates that $60 \%$ of the cracks at $\Delta \sigma=0.6 \sigma_{\mathrm{y}}$ possesses size less than $10 \mu \mathrm{m}$. On the other hand, almost $60 \%$ of cracks bear size in the range 20 to $60 \mu \mathrm{m}$ for $\Delta \sigma=0.8 \sigma_{\mathrm{y}}$ and about $75 \%$ of cracks have sizes in the range 20 to $60 \mu \mathrm{m}$ at $\Delta \sigma=1.0 \sigma_{\mathrm{y}}$. These results obviously indicate that majority of the cracks at low stress range have lower size compared to that of the majority of the 

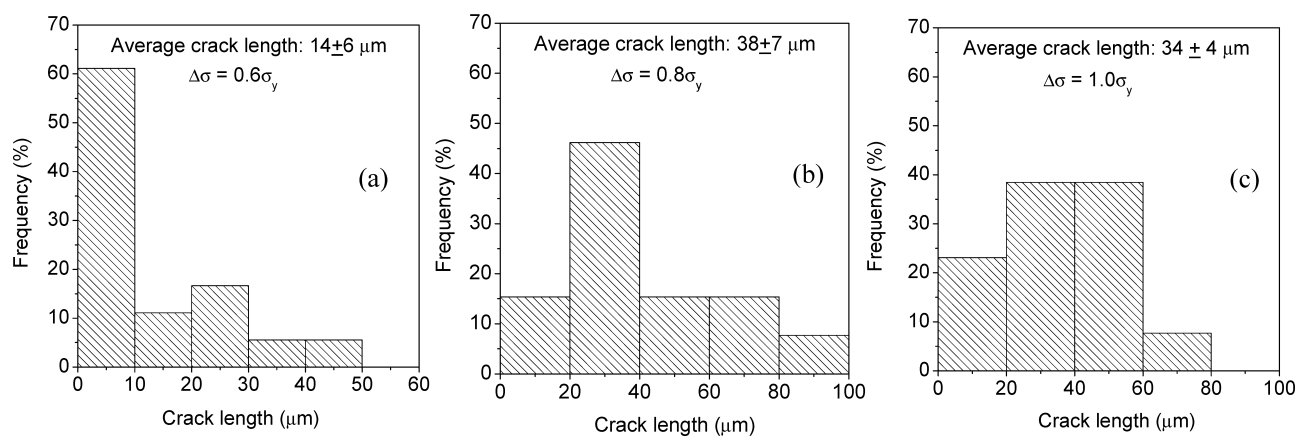

Fig. 6. Size distribution of grain boundary cracks in the investigated IF steel at different applied stress ranges of: (a) $0.6 \sigma_{\mathrm{y}},(\mathrm{b}) 0.8 \sigma_{\mathrm{y}}$ and (c) $1.0 \sigma_{\mathrm{y}}$.
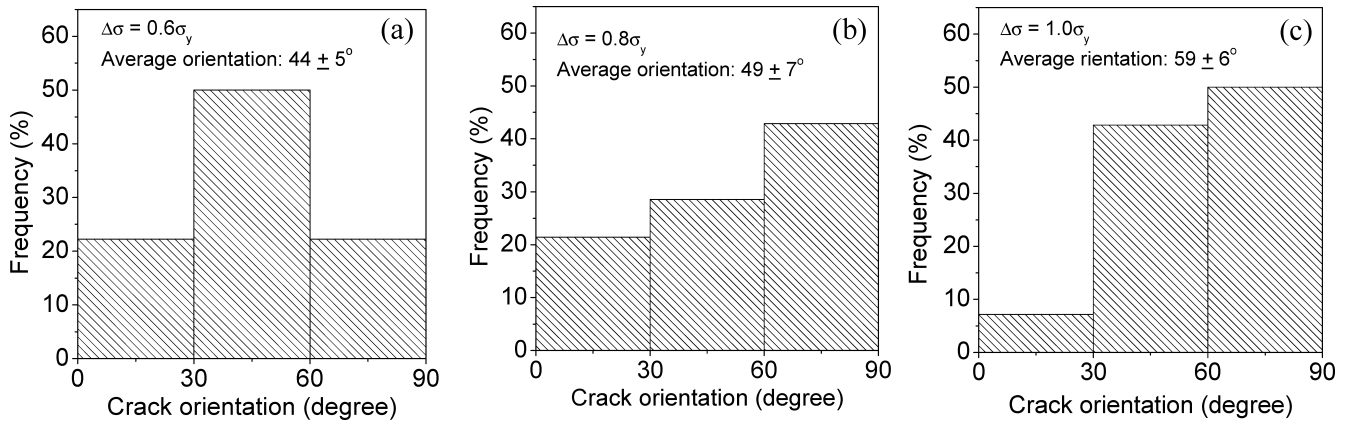

Fig. 7. Distribution of the orientation of grain boundary cracks in the investigated IF steel at different applied stress ranges of: (a) $0.6 \sigma_{\mathrm{y}}$, (b) $0.8 \sigma_{\mathrm{y}}$ and (c) $1.0 \sigma_{\mathrm{y}}$.

cracks generated at higher stress ranges. The observed size distribution of the cracks thus indicates that initiated cracks get the opportunity to grow at higher stress differentials used for crack initiation studies.

The orientations of the observed grain boundary cracks with respect to loading axis were next analyzed and the recorded data are depicted in Fig. 7. It can be noted from this figure that the majority of cracks initiated at $\Delta \sigma=$ $0.6 \sigma_{\mathrm{y}}$ bear orientation between 30 to $60^{\circ}$ whereas at higher stress ranges larger amount of cracks bear orientation greater than $60^{\circ}$. The average angle of orientation of the grain boundary cracks with the loading axis for $\Delta \sigma=0.6$, 0.8 and $1.0 \sigma_{\mathrm{y}}$ were found to be $44 \pm 5,49 \pm 7$ and $59 \pm 6^{\circ}$ respectively. These results indicate that crack initiation occurs primarily in the direction of maximum shear planes, which coincide with the available grain boundary orientations in the microstructure. The higher angle of crack orientation at higher stress levels can be attributed either to the possible joining of more than one crack or extension of the cracks through adjacent grain boundaries. In summary it can be inferred that the average size of the initiated cracks (at the lowest $\Delta \sigma$ of $0.6 \sigma_{\mathrm{y}}$ ) in the investigated steel is $14 \pm 6 \mu \mathrm{m}$ and their average orientation with the loading axis is approximately $45^{\circ}$.

\subsection{Crack Initiation in Ferrite Grain Body}

In comparison to the number of cracks encountered at grain boundaries, cracks observed inside grain body were a few in number. The average crack lengths at $\Delta \sigma=0.6,0.8$ and $1.0 \sigma_{\mathrm{y}}$ were found to be $8 \pm 5,15 \pm 2$ and $33 \pm 8 \mu \mathrm{m}$ respectively. The average length of cracks in the grain body at lower stress ranges is thus found to be considerably smaller than the average length of cracks at grain boundary. A com-

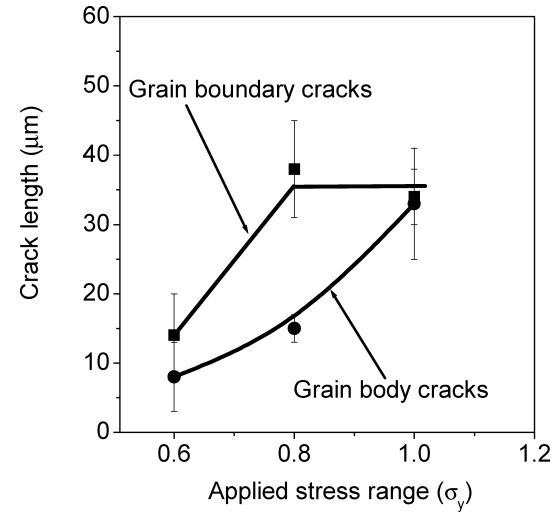

Fig. 8. Variation of average crack lengths with applied stress range.

parison of the crack lengths in grain body and at the grain boundary at different stress levels is made in Fig. 8. While the crack length in the grain body continuously increases with increasing applied stress range, the length of the grain boundary cracks reaches a plateau at stress range around $0.8 \sigma_{\mathrm{y}}$. Interestingly the length of the grain body cracks also meets this plateau at $1.0 \sigma_{\mathrm{y}}$. The average length of the grain boundary cracks at $\Delta \sigma=0.8 \sigma_{\mathrm{y}}$ is marginally higher than that at $\Delta \sigma=1.0 \sigma_{\mathrm{y}}$, but this is an apparent observation. Because within the estimated scatter, the average (grain boundary) crack lengths at $\Delta \sigma=0.8$ and at $\Delta \sigma=1.0 \sigma_{\mathrm{y}}$ are indistinguishable. The average orientation of the grain body cracks with respect to the loading axis was found to be $60 \pm 16,63 \pm 12$ and $82 \pm 2^{\circ}$ for the applied stress ranges of $0.6,0.8$ and $1.0 \sigma_{\mathrm{y}}$ respectively. The higher angle of grain body crack orientation infers that crack initiation in grain body is dominated by normal stresses. 
The salient features of the initiated cracks in IF steel can be summarized as: (i) the average length of cracks initiated at grain boundaries is larger than the average length of cracks initiated inside grain body, (ii) the length of an initiated crack in grain body is always smaller at lower applied stress ranges, (iii) at lower $\Delta \sigma$, orientation of grain boundary cracks is close to $45^{\circ}$, whereas at higher $\Delta \sigma$ orientation of these cracks with respect to loading axis increases, and (iv) the orientation of the grain body cracks even at low stress level is greater than $45^{\circ}$, and the average angle of orientation of these cracks increases like that of grain boundary cracks with increased magnitude of $\Delta \sigma$.

\subsection{Mechanism of Crack Initiation in the Investigated Steel}

The nature, size and orientation of the various initiated cracks a-priori indicate that the mechanisms of crack initiation at the grain boundary and in the grain body of IF steel are different. The initiation of cracks in the grain body is commonly considered to occur within the slip bands in single phase material. The slip bands in BCC ferritic structure of IF steel does not bear a systematic regular pattern like that observed in FCC materials. ${ }^{819)}$ The grain body crack initiation in the investigated steel was observed within the slip bands but the majority of the cracks were different than what is commonly encountered in polycrystalline metals and alloys. It is noted from Fig. 4 that several irregular voids initiate inside the slip bands and appear to act as the origin of the grain body cracks. It is considered here that these irregular voids inside the slip bands either grow and/or coalesce to form cracks exhibiting low aspect ratio (length/width). As a consequence, these cracks are not sharp and do not grow considerably. Typical slip bands in the ferritic structure are shown in Fig. 4(a). The formation of voids and cracks with low aspect ratio, as marked with arrows, are depicted in Fig. 4(b). The formation of voids and their gradual coalescence is illustrated in Fig. 4(c). In addition, some cracks with sharp tips, which were occasionally observed and are not associated with any slip band are shown in Fig. 4(d).

It has been discussed earlier that cracks at grain boundaries commonly bear an orientation approximately $45^{\circ}$ to the loading axis in IF steel. Typical such cracks are described in Fig. 3. The phenomena that maximum shear occurs at $45^{\circ}$ to the loading axis and that the grain boundary cracks are commonly oriented to this direction, assist to infer that grain boundary cracks are predominately influenced by shear stresses. In Fig. 3(b) one can note the impingement of shear bands with grain boundaries, but these impingements do not significantly influence the formation of cracks at grain boundaries. It is obvious from these figures that several voids are formed at grain boundaries as shown by arrow marks in Fig. 3(b). Hence it is considered that separation of grain boundary at small segments, nucleation and growth of small voids at the grain boundary and subsequent joining of the separated segments and voids lead to the formation of grain boundary cracks. The segmental separation or the void nucleation at grain boundaries may be assisted by impingement of slip lines on the grain boundaries. At low stress ranges the probability of joining of the initiated cracks is low and hence one finds small av- erage crack length at low stress ranges. But at higher stress ranges the neighbouring initiated cracks join with each other leading to the observed average higher crack length at $\Delta \sigma=0.8$ and $1.0 \sigma_{\mathrm{y}}$.

The mechanism of crack initiation in the grain body and at the grain boundary of single-phase materials has been discussed by several earlier investigators. ${ }^{6,20-23)}$ Essmann et $a l .{ }^{6)}$ have proposed crack initiation in the grain body of single phase fcc metals occurs inside slip bands. In their proposed micro-mechanism for crack initiation inside a grain body these investigators first considered that persistent slip bands (PSBs) lead to protrusions (intrusions and extrusions) on specimen surface during cyclic loading. The interface between the PSB and the matrix of a material is a plane of discontinuity across which there are abrupt gradients in the density and distribution of dislocations. These interfaces were considered to serve as preferential sites for fatigue crack nucleation. Long et $a$ l. $^{23)}$ have extended the same model for fatigue crack initiation along slip bands in bcc materials like metastable- $\beta$ titanium alloy. The experimental evidence of crack initiation at the PSB-matrix-interface has been reported by Hunsche et $a l^{20)}$ and $\mathrm{Ma}$ et $a l^{21,22)}$ for copper. Hu et al. ${ }^{24)}$ have suggested an alternate proposal that elastic-plastic incompatibility cause slip band crack initiation in titanium alloys. The elastic-plastic incompatibility causing crack nucleation in a grain body can be explained by the existence of an inhomogeneous stress or strain distribution inside the grain body. The inhomogeneity in the stress/strain distribution is more near the grain boundary ${ }^{25,26)}$ and this would, therefore, preferably cause the formation of grain body cracks near the grain boundary.

Based on the idea that grain boundaries act as obstacles to PSBs, Mughrabi ${ }^{27)}$ and Christ et al ${ }^{28)}$ have proposed a slip-induced intergranular crack model or PSB-grain boundary crack model. According to this model, an intergranular fatigue crack can be caused by the stress concentration due to dislocation pile-ups against a grain boundary. Zhang et al. ${ }^{29}$ ) have explained the mechanism for grain boundary crack nucleation by suggesting that slip band impingement against grain boundaries produces many microsplits at the grain boundaries and these micro-splits join to form small cracks. Hu et al. ${ }^{24)}$ have inferred that the elastic-plastic incompatibility is the reason for the formation of cracks at grain boundary.

Several investigators ${ }^{24,29-32)}$ have examined crack initiation in different iron and iron-carbon alloys. Tanaka et al. ${ }^{32)}$ has observed that under reversed bending and axial stresses $(R=-1)$, cracks nucleate always at grain boundaries, but under alternating axial stresses with $R=0$, cracks nucleate along slip bands inside grains of a pure iron. Whereas, Tokaji et al. ${ }^{31)}$ have found that the cracks generally occur in ferrite grains when the grain size is finer, but these are initiated at grain boundaries in coarse grained $0.11 \% \mathrm{C}$ steel. Later, Zhang et al. ${ }^{29)}$ have reported that the most favourable site for crack nucleation in $0.1 \% \mathrm{C}$ steel is the grain boundary. Rios et al., ${ }^{30)}$ on the other hand, have observed that crack initiation occurs only along the slip bands inside the ferrite phase of a $0.4 \% \mathrm{C}$ steel. In bcc single-phase titanium alloy, $\mathrm{Hu}$ et al. $^{24)}$ have found that fatigue cracks predominantly initiate either at grain boundaries or at slip 
bands in the vicinity of grain boundaries.

In the present investigation, fatigue crack initiation has been observed both at grain boundary and inside grain body in IF steel as discussed in the previous sections. An attempt has been made to analyze the observed crack initiation behaviour in this steel in the perspective of the earlier studies in single-phase materials. The formation of slip band inside the grain body, slip band impingement at grain boundary and elastic-plastic incompatibility, as reported by earlier investigators, are also considered here as the main causes for crack initiation in the investigated steel. The formation of irregular voids inside slip bands and their role on the formation of grain boundary cracks are considered here as some new observations of interest. The observed splits at grain boundary of the steel due to slip band impingement is in agreement with earlier studies, but initiation and growth of small voids at the grain boundary and subsequent joining of these with other voids and splits appear specific for ductile bcc materials like IF steel.

\section{Conclusions}

The following conclusions can be drawn from the study of fatigue crack initiation in the selected interstitial free steel:

(i) Cracks nucleate both at grain boundary and inside ferrite grain body in the investigated domain of $\Delta \sigma=0.6$ to $1.0 \sigma_{\mathrm{y}}$.

(ii) The average length of the initiated cracks at grain boundaries is larger in size compared to that of grain body cracks.

(iii) Ferrite-ferrite grain boundaries are found to be significantly preferred crack initiation sites in comparison to ferrite grain body.

(iv) The formation of slip bands inside the grain body, slip band impingement at grain boundary and elastic-plastic incompatibility synergistically influence to cause crack initiation in the investigated IF steel.

(v) Orientation of the initiated cracks is closer to $45^{\circ}$ with respect to the loading axis for grain boundary cracks, whereas this is greater than $60^{\circ}$ for grain body cracks.

(vi) The formation of irregular voids inside slip bands, initiation and growth of small voids at the grain boundary and subsequent joining of these with other voids and splits appear specific for ductile bcc materials like IF steel.

\section{REFERENCES}

1) G. H. Akbari, C. M. Sellars and J. A. Whiteman: Acta Mater, 45
(1997), 5047.

2) H. Takechi: Proc. IF Steels 2003, ISIJ, Tokyo, (2003), 63.

3) J. J. Jonas, L. Kestens and A. O. Humphreys: Proc. IF Steels 2003, ISIJ, Tokyo, (2003), 393.

4) A. J. Deardo: Int. Mater. Rev., 48 (2003), 371.

5) R. O. Ritchie and J. Lankford: Proc. Small Fatigue Cracks, ed. by R. O. Ritchie, J. Lankford, The Metallurgical Society Inc., New York, (1986), 1.

6) U. Essman, U. Gosele and H. Mughrabi: Philos. Mag. A, 44 (1981), 405.

7) J. G. Antonopoulos, L. M. Brown and A. T. Winter: Philos. Mag., 34 (1976), 549.

8) S. Suresh: Fatigue of Materials, 2nd ed., University of Cambridge, UK (1998), 141, 222, 541.

9) K. S. Chan and J. Lankford: Scr. Metall., 17 (1983), 529.

10) A. Navarro and E. R. de los Rios: Fatigue Fract. Eng. Mater. Struct., 11 (1988), 383.

11) K. Hussain, E. R. de los Rios and A. Navarro: Eng. Fract. Mech., 44 (1993), 425.

12) A. Danie'lou, J. Rivat, M. Robillard, J. Stolarz and T. Magnin: Mater. Sci. Eng., A319-321 (2001), 550

13) C. Sommer, H. Mughrabi and D. Lochner: Acta Metall. Mater, 46 (1998), 1527.

14) K. K. Ray, N. Narasaiah and R. Sivakumar: Mater. Sci. Eng. A, A372 (2004), 81.

15) N. Narasaiah and K. K. Ray: "Small crack formation in a low carbon steel with banded ferrite-pearlite structure," Mater. Sci. Eng. A, in press.

16) Japanese Standard JISG-0555, Microscopic Testing Method for the Non-metallic Inclusions of Steels, (2003).

17) G. E. Vander Voort: Metallography Princeples and Practice, McGraw Hill Book Co., New York, (1984), 488.

18) ASTM Standard E 8M-03, Standard Test Method for Tension Testing of Metallic Materials (Metric), ASTM Annual Book of Standards, Vol. 03.01, ASTM, West Conshohocken, PA, (2003).

19) W. H. Kim and C. Laird: Acta Metall., 26 (1978), 789.

20) A. Hunsche and P. Neumann: Acta Metall., 34 (1986), 207.

21) B. T. Ma and C. Laird: Acta Metall., 37 (1989), 325.

22) B. T. Ma and C. Laird: Acta Metall., 37 (1989), 337.

23) M. Long, R. Crooks and H. J. Rack: Acta Mater, 47 (1999), 661.

24) Y. M. Hu, W. Floer, U. Krupp and H. J. Crist: Mater. Sci. Eng. A, A278 (2000), 170.

25) K. K. Ray and D. Mondal: Metall. Trans. A, 23A (1992), 3309.

26) S. Ankem and H. Margolin: Metall. Trans. A, 17A (1986), 2209.

27) H. Mughrabi: Defects, Fracture and Fatigue, ed. by G. C. Sih and J. W. Provan, Martinus Nijhoff, The Hague, (1983), 139.

28) H. J. Christ, H. Mughrabi and C. Witting-Link: Basic Mechanism in Faitgue of Metals, ed. by P. Lukas and J. Polak, Elsevier, Amsterdam, (1988), 83.

29) M. Zhang, P. Yang and T. Yuxu: Int. J. Fatigue, 21 (1999), 823.

30) E. R. De Los Rios, H. J. Mohamed and K. J. Miller: Fatigue Fract. Eng. Mater. Struct., 8 (1985), 49.

31) K. Tokaji, T. Ogawa and Y. Harada: Fatigue Fract. Eng. Mater. Struct., 9 (1986), 205.

32) K. Tanaka and Y. Akinawa: Fatigue 87, EMAS, Warley, UK, (1987), 739. 